\title{
RESEARCH
}

Open Access

\section{Non -fatal overdose among people who inject drugs in Tehran, Iran}

\author{
Mehdi Noroozi ${ }^{1}$, Peter Higgs ${ }^{2}$, Azadeh Bayani ${ }^{3}$, Bahram Armoon ${ }^{4 *}$, Ali Nazeri Astaneh ${ }^{5}$, \\ Ladan Fattah Moghaddam ${ }^{6}$ and Mohammad Askari $^{7}$
}

\begin{abstract}
Background: With increasing frequencies of non-fatal overdose in people who inject drugs (PWID), it is essential to improve our knowledge about associated risk factors for overdose to inform overdose prevention and assistance programs. The aim of present study was to determine the prevalence of non-fatal overdose and the associated risk factors among PWID in Tehran, Iran.
\end{abstract}

Methods: Snowball sampling was used to collect data from 465 participants in Tehran using a cross-sectional survey. Consenting participants who reported drug injecting in the past month and were able to speak and comprehend Farsi enough to respond to survey questions were interviewed. The endpoint of interest was non-fatal overdose in the previous 6 months, or answering "Yes" to the question: "In the last six months, have you ever overdosed by accident? (at least once)". We used STATA v. 14 for this analysis. Statistical significance was defined as $p<0.05$ for all analyses.

Results: Of 465 PWIDs who participated in this study, all were male, and about half had less than a high school education. The prevalence of self-reported non-fatal overdose in the past 6 months was 38\% (C195\%: 34, 43\%). Our findings indicate that characteristics and behaviors that were associated with an increased risk of experiencing an overdose in the past 6 months were drug use initiation under 22 years ( $A O R=2.2, P<0.05$ ), using methamphetamine ( $A O R=2.8, P<0.05$ ), and using multiple drugs at the same time ( $A O R=2.1, P<0.05)$. Also, more recent initiates to injecting ( $<2$ years) had an increased risk of experiencing an overdose in the past 6 months. The odds of experiencing a non-fatal overdose among PWIDs who regularly attended NSP were 0.6 times less than for those who did not attend regularly ( $\mathrm{OR}=0.6,95 \% \mathrm{Cl}: 0.2-0.9)$.

Conclusion: Methamphetamine and alcohol use were the most significant association for non-fatal overdose among PWIDs. Our results indicate that intervention and prevention initiatives seeking to reduce overdoses among PWIDs should not only be focused on the primary drug used but also the use of alcohol and poly-drug use.

Keywords: Non-fatal, Overdose, People who inject drugs, Methamphetamine, Alcohol use

\footnotetext{
* Correspondence: Bahramarmun@gmail.com

${ }^{4}$ Social Determinants of Health Research Center, Saveh University of Medical Sciences, Saveh, Iran

Full list of author information is available at the end of the article
}

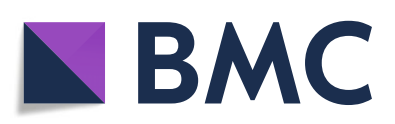

(c) The Author(s). 2020 Open Access This article is licensed under a Creative Commons Attribution 4.0 International License, which permits use, sharing, adaptation, distribution and reproduction in any medium or format, as long as you give appropriate credit to the original author(s) and the source, provide a link to the Creative Commons licence, and indicate if changes were made. The images or other third party material in this article are included in the article's Creative Commons licence, unless indicated otherwise in a credit line to the material. If material is not included in the article's Creative Commons licence and your intended use is not permitted by statutory regulation or exceeds the permitted use, you will need to obtain permission directly from the copyright holder. To view a copy of this licence, visit http://creativecommons.org/licenses/by/4.0/ The Creative Commons Public Domain Dedication waiver (http://creativecommons.org/publicdomain/zero/1.0/) applies to the data made available in this article, unless otherwise stated in a credit line to the data. 


\section{Background}

Global estimates suggest there are 16 million people who inject drugs (PWIDs) [1] and drug injection is one of the most important public health issues currently facing Iran [2]. According to local studies, it is estimated that there are between 170,000 and 230,000 PWIDs with around $15 \%$ of them are infected with HIV [3]. Overdose accounts for almost one-third of drug-associated deaths among opiate using PWIDs [4, 5] and is increasing across different contexts. Studies suggest more than two thirds of drug users have experienced at least one nonfatal overdose in their life [6] with more than two million drug-related emergency department visits having occurred in 2004 [7].

Considerable morbidity has been associated with nonfatal overdose including physical injuries, aspirationrelated lung injury and infections, seizures, and peripheral neuropathy [8]. Previous experience of a non-fatal overdose is a significant risk factor for future overdose (both fatal and non-fatal) and is related with several health risks such as cognitive impairment and muscular dysfunction also high healthcare costs [9, 10]. Studies has also recorded important overlap between the mutual relationship [10-12] of fatal and non-fatal overdose [13]. Other correlates of non-fatal overdose include "polysubstance use" for example, taking multiple kinds of substances that can act together to increase the risk of overdose, such as the simultaneous use of opioids and alcohol, or opioids and benzodiazepines, as well as other factors such as homelessness, injecting in public places such as streets or abandoned houses, and police encounters [11-15]. Few previous studies in Iran investigated the prevalence of non-fatal overdose and their associated risk factors $[16,17]$. With non-fatal overdose increasing among PWIDs, it is essential to improve our knowledge about this problem and their associated risk factors to inform overdose prevention and assistance programs. The primary aims of our study was to determine the prevalence of non-fatal overdose and any associated risk factors among PWIDs in Tehran, Iran.

\section{Methods}

The study population and data collection procedures have been described in detail elsewhere [18] but briefly we outline the process below.

\section{Study design}

A cross-sectional study was conducted among current PWIDs to assess prevalence and risk factors for recent overdose in Tehran, in 2016.

\section{Dependent variable}

Self-reported non-fatal overdose in the last 6 months.

\section{Study sampling}

Our final sample size was a total of 485 and we excluded 20 individuals because of not responding to the questions or dissatisfaction with participating in the study.

465 PWIDs were recruited using snowball sampling and convenience sampling. Eligible participants were then given the opportunity to invite their peers to also participate in the study - all participants were reimbursed 15,000 Tomans (Iranian currency) for their involvement in the study.

\section{Inclusion and exclusion criteria}

To be eligible for the study, participants were required to be over 18 years old and to have injected illicit drugs at least once in the past month. Additional eligibility criteria were ability to speak and comprehend Farsi enough to respond to survey questions, and to provide informed consent.

\section{Study instruments and procedure}

Face-to-face interviews were conducted by trained interviewers using a structured questionnaire. Interviews included socio-demographic information (i.e., age, educational attainment, marital status, income and employment status), drug use history (i.e., age of initiation, past 6 months use of specific drugs including heroin, methamphetamine, prescription drugs, cannabis), history of prison, needle syringe program (NSP) exposure, use of poly drugs and alcohol use. All behavioral questions referred to the 6-months prior to completing the interview. Alpha test of the internal consistency of the questionnaire among demonstrated Cronbach's a values between 0.88 and 0.90 . No identifying information was collected from questionnaire respondents.

\section{Ethics approval and consent to participate}

Approval to conduct the study was granted by the Ethics Committee of University of Social Welfare and Rehabilitation Sciences. Informed written consent was received from all participants. The Ethical code was IR.USWR.REC.1398.086.

\section{Outcome definition}

Overdose has been defined as an action with the following characteristics: the loss of consciousness, presenting blue skin color, collapsing, inability to wake up, encountering convulsions, experiencing difficulties with breathing, myocardial infarction, or even death occurred during drug use. This definition was in line with the studies conducted in Adelaide, Australia [19], and San Francisco, California [20]. We created a list of above mentioned characteristics and in cases that participants indicated any of these characteristics we considered them as PWIDs who experienced overdose. We asked study participants to report on any overdose experience over the past 6 months using this definition. 


\section{Statistical analysis}

Descriptive statistics were used to characterize the demographics, drug use histories and overdose histories of the overall study population. Firstly, we considered the bivariable relationships between all independent variables and the prevalence of non-fatal overdose using Pearson's Chi-square test. After checking for collinearity, variables with $p$-value $<0.2$ were included in the multiple logistic regression model. Then, variables were eliminated from the multivariable models using stepwise selection. The final model included only variables with $p<0.05$. We reported the adjusted odds ratio (aOR) point estimate and $95 \%$ confidence interval $(95 \% \mathrm{CI})$ as the effect measure. We used STATA v. 14 for this analysis. Statistical significance was defined as $p<0.05$ for all analyses.

\section{Results}

Of 465 PWIDs who participated in this study, all were male, and about half had less than a high school education.

The prevalence of non-fatal overdose in the past 6 months was 38\% (95\% CI: 34, 43\%). The main sociodemographic characteristics of PWIDs who reported overdose in comparison with PWIDs who did not reported any overdose are shown in Table 1.

\section{Bivariate analyses}

In bivariate analyses, there were a number of statistically significant differences in socio- economic characteristics (age) and drug use characteristics between those who had and had not witnessed an overdose.

Participants who reported a history of overdose compared to those who did not were significantly more likely to have started their drug use before the age of 22 . They also reported an injecting drug use career of less 2 years. They were using the NSP regularly, were alcohol and methamphetamine users.

\section{Multiple logistic regression analyses}

In the final multiple logistic regression model (Table 2) the characteristics and behaviors that were associated with an increased risk of experiencing an overdose in the past 6 months are presented. There were no significant associations between non-fatal overdose and socioeconomic characteristics (age, education and income).

Age under 20 years (with those who are younger being at higher risk) was significantly associated with overdose (AOR $=2.2$, 95\% CI: 1.8-5.7, $P<0.01$ ). Results showed that starting injecting within the last 2 years was associated with an increased risk of experiencing an overdose in the past 6 months. Recent recruits to injecting were 2.7 times more likely to have had an overdose (AOR 2.7; 95\% CI 1.6-4.61, $P<0.02$ ).
Table 1 Characteristics of people who inject drugs and overdose history, Tehran, Iran 2016

\begin{tabular}{|c|c|c|c|}
\hline \multirow[t]{3}{*}{ Characteristics } & \multicolumn{2}{|c|}{ Self-reported overdose past six months } & \multirow{3}{*}{$\begin{array}{l}P \text { - } \\
\text { value }\end{array}$} \\
\hline & $\begin{array}{l}\text { Yes } \\
(n=180)\end{array}$ & $\begin{array}{l}\text { No } \\
(n=285)\end{array}$ & \\
\hline & $\mathrm{N}(\%)$ & $\mathrm{N}(\%)$ & \\
\hline \multicolumn{4}{|l|}{ Age (year) } \\
\hline$<30$ & $103(57)$ & $171(60)$ & 0.04 \\
\hline $30-39$ & $54(30)$ & $77(27)$ & \\
\hline $40+$ & $23(13)$ & $37(13)$ & \\
\hline Age (Mean + SD) & $27.4 \pm 7.8$ & $33.2 \pm 7.2$ & 0.04 \\
\hline \multicolumn{4}{|l|}{ Education } \\
\hline$>$ High school & $108(60)$ & $145(51)$ & 0.05 \\
\hline$<$ High school & $72(40)$ & $140(49)$ & \\
\hline \multicolumn{4}{|l|}{ Marital status } \\
\hline Single & $94(52)$ & $134(47)$ & 0.27 \\
\hline Married & $86(48)$ & $151(53)$ & \\
\hline \multicolumn{4}{|l|}{ Employment Status } \\
\hline Unemployed & $99(55)$ & $134(47)$ & 0.09 \\
\hline Employed & $81(45)$ & $151(53)$ & \\
\hline \multicolumn{4}{|l|}{ Income (USD) } \\
\hline$>150$ & $68(38)$ & $128(45)$ & 0.12 \\
\hline$<150$ & $112(72)$ & $157(55)$ & \\
\hline \multicolumn{4}{|c|}{ Methamphetamine use } \\
\hline Yes & $86(48)$ & $95(33)$ & 0.002 \\
\hline No & $94(52)$ & $190(67)$ & \\
\hline \multicolumn{4}{|l|}{ Alcohol use } \\
\hline Yes & $80(45)$ & $100(35)$ & 0.04 \\
\hline No & $100(55)$ & $185(65)$ & \\
\hline \multicolumn{4}{|c|}{ Age of drug initiation (year) } \\
\hline$<22$ & $101(56)$ & $128(45)$ & 0.01 \\
\hline $22+$ & $79(44)$ & $157(55)$ & \\
\hline \multicolumn{4}{|c|}{ Age of onset to injection } \\
\hline$<22$ & $117(65)$ & $100(35)$ & 0.001 \\
\hline $22+$ & $63(35)$ & $185(65)$ & \\
\hline \multicolumn{4}{|c|}{ Duration of inject drug } \\
\hline$\leq 2$ & $94(52)$ & $95(33)$ & 0.001 \\
\hline$>2$ & $86(48)$ & $190(67)$ & \\
\hline Poly drug & & & 0.08 \\
\hline Yes & $81(45)$ & $105(37)$ & \\
\hline No & $99(55)$ & $180(63)$ & \\
\hline \multicolumn{4}{|l|}{ History of prison } \\
\hline Yes & $45(25)$ & $57(20)$ & 0.2 \\
\hline No & $135(75)$ & $228(80)$ & \\
\hline \multicolumn{4}{|c|}{ Needle and syringe Program exposure (counseling service) } \\
\hline Regular & $71(40)$ & $180(63)$ & 0.001 \\
\hline Irregular & $109(60)$ & $105(37)$ & \\
\hline
\end{tabular}


Table 2 Multiple logistic regression and Adjust Odds Ratio (AOR) of factors associated with non-fatal overdose among PWID (last 6 months)

\begin{tabular}{|c|c|c|c|}
\hline \multirow[t]{2}{*}{ Characteristics } & \multicolumn{2}{|c|}{ Over dose } & \multirow{2}{*}{$\begin{array}{l}P \text { - } \\
\text { Value }\end{array}$} \\
\hline & $\overline{A O R}$ & (\% Cl95) & \\
\hline \multicolumn{4}{|l|}{ Age (year) } \\
\hline$<30$ & 1 & $\ldots \ldots \ldots . .$. & - \\
\hline $30-39$ & 1.3 & $(0.1-5.3)$ & 0.3 \\
\hline $40+$ & 1.4 & $(0.2-4.8)$ & \\
\hline \multicolumn{4}{|l|}{ Education } \\
\hline$>$ High school & 1 & $\ldots \ldots \ldots . .$. & - \\
\hline$<$ High school & 1.3 & $(0.8-2.31)$ & 0.4 \\
\hline \multicolumn{4}{|l|}{ Income (USD) } \\
\hline$>150$ & 1 & $\ldots \ldots \ldots . .$. & - \\
\hline$<150$ & 1.65 & $(0.93-2.99)$ & 0.3 \\
\hline \multicolumn{4}{|c|}{ Age of drug initiation (year) } \\
\hline$<20$ & 2.2 & $(1.8-5.7)$ & 0.01 \\
\hline $20+$ & 1 & - & - \\
\hline \multicolumn{4}{|l|}{ Duration of inject drug } \\
\hline$<2$ & 2.7 & $(1.6-4.61)$ & 0.02 \\
\hline$>2$ & 1 & $\ldots \ldots \ldots . .$. & - \\
\hline \multicolumn{4}{|l|}{ Methamphetamine use } \\
\hline Yes & 2.8 & $(1.8-7.4)$ & 0.02 \\
\hline No & 1 & $\ldots \ldots \ldots . .$. & - \\
\hline \multicolumn{4}{|l|}{ Poly Drug } \\
\hline Yes & 2.1 & $(1.4-5.3)$ & \\
\hline No & 1 & $\ldots \ldots \ldots . .$. & 0.01 \\
\hline \multicolumn{4}{|l|}{ Alcohol use } \\
\hline Yes & 2.8 & $(1.2-4.3)$ & 0.01 \\
\hline No & 1 & $\ldots \ldots \ldots . .$. & - \\
\hline \multicolumn{4}{|c|}{ Needle and syringe Program exposure } \\
\hline Regular use of NSP & 0.6 & $(0.2-0.9)$ & 0.01 \\
\hline Irregular use of NSP & 1 & - & - \\
\hline
\end{tabular}

Methamphetamine use was also positively associated with non-fatal overdose among PWID in this study. Individuals using methamphetamine (AOR 2.8; 95\% CI 1.8-7.4, $P<0.02$ ) were 2.8 times more likely to have had an overdose in the previous 6 months.

Our results indicates a significant correlation between poly drug use and overdose. Those PWIDs who reported using multiple drugs at the same time were 2.1 times more likely to have had an overdose (AOR 2.1; $95 \%$ CI 1.4-5.3, $P<0.01$ ).

Our results demonstrated that alcohol use was positively associated with overdose among PWIDs (AOR = 2.8, 95\% CI: 1.2-4.3, $P<0.01$ ).

Finally, our data found that regular NSP use was negatively associated with overdose. Where those attending
NSP were 0.6 times less likely to report overdosing than other participants (AOR $=0.6,95 \%$ CI: $0.2-0.9, P<0.01$ ).

\section{Discussion}

This study assessed the socio-demographic and behavioral risk factors associated with overdose among PWIDs in Tehran. After adjustment, our findings indicate that PWIDs who started using any illicit drug before the age of 20 were more likely to report experiencing an overdose in the 6 months before their interview. The age that individuals start using opioids is also important to know about and understand because evidence suggests those who begin using at an earlier age are more susceptible to drug dependence and other associated social and/or health problems [21-26]. Consistent with previous studies $[27,28]$ our analysis suggests that the participants who started injecting less than 2 years before interview (new injectors), were more likely to report a non-fatal overdose. One possible explanation for this is that those with less injecting experience and lower tolerance are more susceptible. However, this explanation is not universally supported, with other studies noting older injectors are more likely to experience recent overdose suggesting that the risk of overdose increases alongside the length of the drug-using career [13, 29].

Our research establishes that PWIDs who are also using other drugs (poly drug use) in the 6 months before interview was more susceptible to experiencing non-fatal overdose. This is not surprising with a number of previous studies showing poly-drug use is strongly associated with both fatal and non-fatal overdose [13, 20, 29]. These data also highlight the broader challenges faced by polydrug users including living on the streets and exposure to structural issues including violence [30].

Our findings that PWIDs who use alcohol and/or methamphetamine were more likely to report a recent overdose are supported by other empirical data [11, 31]. Previous studies have reported higher prevalence of overdose among injection drug users who also report alcohol consumption $[31,32]$ demonstrating the pharmacological or behavioral interactions between alcohol and injected substances [33].

It is essential to emphasise the significant effect of alcohol in this regard. Alcohol use was commonly reported by participants in our study and prior investigations also indicate an association between greater rates of overdose and alcohol consumption [31, 32].

These data indicate the importance of addressing both drug use and the consumption of alcohol in any harm reduction prevention programs developed to work with PWID in Iran.

The most significant correlation was observed between the use of methamphetamine (injection \& non-injection) 
and overdose. The increasing prevalence of methamphetamine use in Iran may help to explain this finding $[34,35]$.

Based on our findings, PWIDs attending NSP were at lower risk of overdose. Our finding is in line with other studies [36, 37] showing that the provision of other services from needle and syringe programs, including overdose education and providing naloxone can prevent overdose, [37]. Also, other services include, providing counseling and testing PWIDs about substance abuse treatment, HIV, hepatitis C virus (HCV), HBV counseling and testing [38-43], and naloxone for overdose educating PWIDs [44]. Additionally, integrating the health care systems with the services for PWIDs has positive influences both for PWIDs and the society $[45,46]$. It is important to consider that NSP can have significant influences on PWIDs programs. NSP as secondary prevention programs, selling non-prescript syringes in pharmacies, safe dumping of used equipment in injections, and overdose prevention programs among the community, can decrease the risk of injection drug intake and reduce social and medical costs $[36,47,48]$.

\section{Limitation of study}

There are some limitations to our study. As this was a cross-sectional study, no causal inference between overdose and risk factors can be made. Our data are based on participant's self-report and therefore may be subject to misclassification, recall and/or social desirability bias. Furthermore, there was no specific definition for overdose so participant understanding of overdose may not be the same. Limitation was that the obtained data may not be generalized to other groups of PWIDs, is not a random study sample. Besides, the required information was collected on a self-report basis; thus, socially-desired responses are possible, leading to underestimating the non-fatal overdose rate., Another biasing was that, we probed data concerning overdose and disregarded signifying the overdose symptoms in the interviews, e.g., experiencing convulsions and/or the lack of consciousness; due to the use of too strong drugs and the lack of recalling the incidence, PWIDs might have underreported overdose. Eventually, characteristic in the present research was mortality, as we only interviewed the overdose survivors.

\section{Conclusion}

Methamphetamine and alcohol use were the most significant associations for non-fatal overdose among PWIDs in this study. Our findings indicate that any intervention and prevention measures seeking to reduce overdose among PWIDs must address the primary drug being used but also pay attention to the use of alcohol and any other drugs. PWID are more likely than health care workers to be in a position to manage and respond to overdose therefore they must be targeted with overdose prevention education, and trained in the use of naloxone [49]. Harm reduction programs that focus on working with vulnerable and hard-to-reach injection drug users must include the provision of training regarding overdose.

\section{Abbreviations \\ aOR: Adjusted odds ratio; Cl: Confidence interval; NSP: Needle and syringe program; OD: Overdose; PWIDs: People who inject drugs}

\section{Acknowledgements \\ The authors would like to acknowledge the contributions of Cinta Folch to the work of this review of the evidence.}

\section{Authors' contributions}

Study concept and design: BA and MN. Analysis and interpretation of data: $M N$. Drafting the manuscript: BA, MN and AB. Critical revision of the manuscript: PH, ANA, LFM, MA and AB. All authors read and approved the final manuscript. The authors declare that this manuscript has not been presented to any other journal for publication. All authors read and approved the final manuscript.

\section{Funding}

This study, funded by University of Social Welfare and Rehabilitation Sciences.

\section{Availability of data and materials}

The datasets used and/or analyzed during the current study are available from the corresponding author on reasonable request.

\section{Ethics approval and consent to participate}

Approval to conduct the study was granted by the Ethics Committee of University of Social Welfare and Rehabilitation Sciences. Informed written consent was received from all participants. The Ethical code was IR.USWR.REC.1398.086. All participants were informed that their participation was voluntary and the procedure used did not pose any potential risk and their identities will be kept strictly confidential. Informed written consent forms were taken from all participants before participation.

Consent for publication

Not applicable.

\section{Competing interests}

The authors declare that there are no conflicts of interest.

\section{Author details}

${ }^{1}$ Social Determinants of Health Research Center, University of Social Welfare and Rehabilitation Sciences, Tehran, Iran. ${ }^{2}$ Department of Public Health, School of Psychology and Public Health, La Trobe University, Melbourne, Australia. ${ }^{3}$ Student Research Committee, School of Allied Medical Sciences, Shahid Beheshti University of Medical Sciences, Tehran, Iran. ${ }^{4}$ Social Determinants of Health Research Center, Saveh University of Medical Sciences, Saveh, Iran. ${ }^{5}$ Department of Psychiatry, University of Social Welfare and Rehabilitation Science, Tehran, Iran. ${ }^{6}$ Department of Nursing, Faculty of Nursing and Midwifery, Tehran Medical Sciences, Islamic Azad University, Tehran, Iran. ${ }^{7}$ Pasteur institute of Iran, Tehran, Iran.

Accepted: 9 October 2020

Published online: 14 October 2020

\section{References}

1. Degenhardt L, Peacock A, Colledge S, Leung J, Grebely J, Vickerman P, Stone J, Cunningham EB, Trickey A, Dumchev K. Global prevalence of injecting drug use and sociodemographic characteristics and prevalence of $H I V, H B V$, and HCV in people who inject drugs: a multistage systematic review. Lancet Glob Health. 2017;5(12):e1 192-207.

2. Noroozi M, Sharifi $H$, Noroozi $A$, Ghiasvand $H$, Higgs $P$, Waye $K$, et al. The impact of income inequality in HIV testing among people who inject drugs 
in Tehran, Iran: a blinder-Oaxaca decomposition. J Subst Abus. 2020;25(3): 290-4.

3. Armoon B, Noroozi M, Jorjoran Shushtari Z, Sharhani A, Ahounbar E, Karim S, Ahmadi S, Farhoudian A, Rahmani A, Abbasi M. Factors associated with HIV risk perception among people who inject drugs: findings from a crosssectional behavioral survey in Kermanshah, Iran. J Subst Use. 2018;23(1):63-6.

4. Saini R, Rao R, Parmar A, Mishra AK, Ambekar A, Agrawal A, Dhingra N. Rates, knowledge and risk factors of non-fatal opioid overdose among people who inject drugs in India: a community-based study. Drug Alcohol Rev. 2020;39(1):93-7.

5. Degenhardt L, Bucello C, Mathers B, Briegleb C, Ali H, Hickman M, McLaren J. Mortality among regular or dependent users of heroin and other opioids: a systematic review and meta-analysis of cohort studies. Addiction. 2011; 106(1):32-51.

6. Martins SS, Sampson L, Cerdá M, Galea S. Worldwide prevalence and trends in unintentional drug overdose: a systematic review of the literature. Am J Public Health. 2015;105(11):e29-49.

7. Burns BJ, Phillips SD, Wagner HR, Barth RP, Kolko DJ, Campbell Y, Landsverk J. Mental health need and access to mental health services by youths involved with child welfare: a national survey. J Am Acad Child Adolesc Psychiatry. 2004;43(8):960-70.

8. Warner-Smith M, Darke S, Day C. Morbidity associated with non-fatal heroin overdose. Addiction. 2002;97(8):963-7.

9. Stoové MA, Dietze PM, Jolley D. Overdose deaths following previous nonfatal heroin overdose: record linkage of ambulance attendance and death registry data. Drug Alcohol Rev. 2009;28(4):347-52.

10. Bartu A, Freeman NC, Gawthorne GS, Codde JP, Holman CDAJ. Mortality in a cohort of opiate and amphetamine users in Perth, Western Australia. Addiction. 2004;99(1):53-60.

11. Gossop M, Stewart D, Treacy S, Marsden J. A prospective study of mortality among drug misusers during a 4-year period after seeking treatment. Addiction. 2002:97(1):39-47.

12. Sánchez-Carbonell $X$, Seus $L$. Ten-year survival analysis of a cohort of heroin addicts in Catalonia: the EMETYST project. Addiction. 2000;95(6):941-8.

13. Darke $\mathrm{S}, \mathrm{Hall}$ W. Heroin overdose: research and evidence-based intervention. J Urban Health. 2003:80(2):189-200

14. Vlahov D, Wang C, Ompad D, Fuller CM, Caceres W, Ouellet L, Kerndt P, Des Jarlais DC, Garfein RS. Mortality risk among recent-onset injection drug users in five US cities. Subst Use Misuse. 2008;43(3-4):413-28.

15. Mathers BM, Degenhardt L, Phillips B, Wiessing L, Hickman M, Strathdee SA, Wodak A, Panda S, Tyndall M, Toufik A. Global epidemiology of injecting drug use and HIV among people who inject drugs: a systematic review. Lancet. 2008;372(9651):1733-45.

16. Mehrpour O, Karrari P, Afshari R. Recreational use and overdose of ingested processed cannabis (Majoon Birjandi) in the eastern Iran. Hum Exp Toxicol. 2012;31(11):1188-9.

17. Babak K, Mohammad A, Mazaher G, Samaneh A, Fatemeh T. Clinical and laboratory findings of rhabdomyolysis in opioid overdose patients in the intensive care unit of a poisoning center in 2014 in Iran. Epidemiol Health. 2017;39:e2017050-e.

18. Nazari SSH, Noroozi M, Soori H, Noroozi A, Mehrabi Y, Hajebi A, Sharifi H, Higgs P, Mirzazadeh A. The effect of on-site and outreach-based needle and syringe programs in people who inject drugs in Kermanshah, Iran. Int J Drug Policy. 2016;27:127-31.

19. McGregor C, Darke S, Ali R, Christie P. Experience of non-fatal overdose among heroin users in Adelaide, Australia: circumstances and risk perceptions. Addiction. 1998;93(5):701-11.

20. Ochoa KC, Hahn JA, Seal KH, Moss AR. Overdosing among young injection drug users in San Francisco. Addict Behav. 2001;26(3):453-60.

21. Baldwin P, Shrestha R, Potrepka J, Copenhaver M. The age of initiation of drug use and sexual behavior may influence subsequent HIV risk behavior: a systematic review. Isrn Aids. 2013;976035. https://doi.org/10.1155/2013/ 976035

22. Chen C-Y, Storr CL, Anthony JC. Early-onset drug use and risk for drug dependence problems. Addict Behav. 2009;34(3):319-22.

23. King KM, Chassin L. A prospective study of the effects of age of initiation of alcohol and drug use on young adult substance dependence. I Stud Alcohol Drugs. 2007;68(2):256-65.

24. Bazrafshan MR, Noroozi M, Ghisvand H, Noroozi A, Alibeigi N, Abbasi M, Higgs P, Armoon B. Comparing injecting risk behaviors of long-term injectors with new injectors in Tehran, Iran. Subst Use Misuse. 2019;54(2): 185-90.

25. Ghiasvand H, Bayani A, Noroozi A, Marshall BD, Koohestani HR, Hemmat M, Mirzaee MS, Bayat AH, Noroozi M, Ahounbar E, et al. Comparing injecting and sexual risk behaviors of long-term injectors with new injectors: a metaanalysis. J Addict Dis. 2018;37(3-4):233-44.

26. Noroozi M, Farhadi MH, Armoon B, Farhoudian A, Shushtari ZJ, Sharhani A, Karimi SE, Sayadnasiri M, Rezaei O, Ghiasvand H. Factors associated with time between using a drug and injection initiation among people who inject drugs in Kermanshah, Iran. Int J Adolesc Med Health. 2018.

27. Vallance K, Pauly B, Wallace B, Chow C, Perkin K, Martin G, Zhao J, Stockwell T. Factors associated with public injection and nonfatal overdose among people who inject drugs in street-based settings. Drugs. 2018;25(1):38-46.

28. Colledge S, Peacock A, Leung J, Larney S, Grebely J, Hickman M, Cunningham E, Trickey A, Stone J, Vickerman P. The prevalence of non-fatal overdose among people who inject drugs: a multi-stage systematic review and meta-analysis. Int J Drug Policy. 2019;73:172-84.

29. Darke S, Zador D. Fatal heroin 'overdose': a review. Addiction. 1996;91(12): 1765-72.

30. Hakkarainen P, O'Gorman A, Lamy F, Kataja K. (re) conceptualizing "Polydrug use": capturing the complexity of combining substances. Contemp Drug Probl. 2019;46(4):400-17.

31. Bazazi AR, Zelenev A, Fu JJ, Yee I, Kamarulzaman A, Altice FL. High prevalence of non-fatal overdose among people who inject drugs in Malaysia: correlates of overdose and implications for overdose prevention from a cross-sectional study. Int J Drug Policy. 2015;26(7):675-81.

32. Kinner SA, Milloy M, Wood E, Qi J, Zhang R, Kerr T. Incidence and risk factors for non-fatal overdose among a cohort of recently incarcerated illicit drug users. Addict Behav. 2012;37(6):691-6.

33. Heinze G, Schemper M. A solution to the problem of separation in logistic regression. Stat Med. 2002;21(16):2409-19.

34. Yoosefi Lebni J, Ziapour A, Qorbani M, Baygi F, Mirzaei A, Safari O, Rastegarimehr B, Khosravi B, Mansourian M. The consequences of regular methamphetamine use in Tehran: qualitative content analysis. Subst Abuse Treat Prev Policy. 2020;15(1):33.

35. Noroozi M, Higgs P, Noroozi A, Armoon B, Mousavi B, Alikhani R, Bazrafshan MR, Astaneh AN, Bayani A, Moghaddam LF. Methamphetamine use and HIV risk behavior among men who inject drugs: causal inference using coarsened exact matching. Harm Reduct J. 2020;17(1):66.

36. Semaan S, Fleming P, Worrell C, Stolp H, Baack B, Miller M. Potential role of safer injection facilities in reducing HIV and hepatitis $C$ infections and overdose mortality in the United States. Drug Alcohol Depend. 2011;118(23):100-10.

37. Iversen J, Topp L, Wand H, Maher L. Individual-level syringe coverage among needle and syringe program attendees in Australia. Drug Alcohol Depend. 2012;122(3):195-200.

38. Des Jarlais DC, McKnight C, Goldblatt C, Purchase D. Doing harm reduction better: syringe exchange in the United States. Addiction. 2009;104(9):1441-6.

39. Noroozi M, Noroozi A, Sharifi H, Harouni GG, Marshall BD, Ghisvand H, Qorbani M, Armoon B. Needle and syringe programs and HIV-related risk behaviors among men who inject drugs: a multilevel analysis of two cities in Iran. Int J Behav Med. 2019;26(1):50-8.

40. Noroozi M, Marshall BD, Noroozi A, Armoon B, Sharifi H, Farhoudian A, Ghiasvand H, Vameghi M, Rezaei O, Sayadnasiri M. Do needle and syringe programs reduce risky behaviours among people who inject drugs in Kermanshah City, Iran? A coarsened exact matching approach. Drug Alcohol Rev. 2018;37:5303-8.

41. Karimi SE, Bayani A, Higgs P, Bayat A-H, Hemmat M, Ahounbar E, Armoon B, Fakhri Y. Prevalence and high risk behaviours associated with HCV testing among people who inject drugs: a systematic review and meta-analysis. Subst Abuse Treat Prev Policy. 2020;15(1):1-16.

42. Rezaei O, Ghiasvand H, Higgs P, Noroozi A, Noroozi M, Rezaei F, Armoon B, Bayani A. Factors associated with injecting-related risk behaviors among people who inject drugs: a systematic review and meta-analysis study. J Addict Dis. 2020:1-18.

43. Bayani A, Ghiasvand H, Rezaei O, Fattah Moghaddam L, Noroozi A, Ahounbar E, Higgs P, Armoon B. Factors associated with HIV testing among people who inject drugs: a meta-analysis. J Addict Dis. 2020;38(3):361-74.

44. Des Jarlais DC. Harm reduction in the USA: the research perspective and an archive to David Purchase. Harm Reduct J. 2017:14(1):51. 
45. Des Jarlais DC, Marmor M, Paone D, Titus S, Shi Q, Perlis T, Jose B, Friedman SR. HIV incidence among injecting drug users in New York City syringeexchange programmes. Lancet. 1996;348(9033):987-91.

46. Fischer B, Turnbull S, Poland B, Haydon E. Drug use, risk and urban order: examining supervised injection sites (SISs) as 'governmentality'. Int J Drug Policy. 2004;15(5-6):357-65.

47. Des Jarlais DC, Semaan S. HIV prevention for injecting drug users: the first 25 years and counting. Psychosom Med. 2008;70(5):606-11.

48. Schackman BR, Gebo KA, Walensky RP, Losina E, Muccio T, Sax PE, Weinstein MC, Seage GR 3rd, Moore RD, Freedberg KA.. The lifetime cost of current human immunodeficiency virus care in the United States. Med Care. 2006 ;44(11):990-7. https://doi.org/10.1097/01.mlr.0000228021.89490.2a.

49. Baca CT, Grant KJ. Take-home naloxone to reduce heroin death. Addiction. 2005;100(12):1823-31.

\section{Publisher's Note}

Springer Nature remains neutral with regard to jurisdictional claims in published maps and institutional affiliations.

Ready to submit your research? Choose BMC and benefit from:

- fast, convenient online submission

- thorough peer review by experienced researchers in your field

- rapid publication on acceptance

- support for research data, including large and complex data types

- gold Open Access which fosters wider collaboration and increased citations

- maximum visibility for your research: over $100 \mathrm{M}$ website views per year

At BMC, research is always in progress.

Learn more biomedcentral.com/submissions 